\title{
Investigation of copy number variations on chromosome 21 detected by comparative genomic hybridization (CGH) microarray in patients with congenital anomalies
}

Wenfu Li, Xianfu Wang and Shibo Li

\begin{abstract}
Background: The clinical features of Down syndrome vary among individuals, with those most common being congenital heart disease, intellectual disability, developmental abnormity and dysmorphic features. Complex combination of Down syndrome phenotype could be produced by partially copy number variations (CNVs) on chromosome 21 as well. By comparing individual with partial CNVs of chromosome 21 with other patients of known CNVs and clinical phenotypes, we hope to provide a better understanding of the genotype-phenotype correlation of chromosome 21 .
\end{abstract}

Methods: A total of 2768 pediatric patients sample collected at the Genetics Laboratory at Oklahoma University Health Science Center were screened using CGH Microarray for CNVs on chromosome 21.

Results: We report comprehensive clinical and molecular descriptions of six patients with microduplication and seven patients with microdeletion on the long arm of chromosome 21. Patients with microduplication have varied clinical features including developmental delay, microcephaly, facial dysmorphic features, pulmonary stenosis, autism, preauricular skin tag, eye pterygium, speech delay and pain insensitivity. We found that patients with microdeletion presented with developmental delay, microcephaly, intrauterine fetal demise, epilepsia partialis continua, congenital coronary anomaly and seizures.

Conclusion: Three patients from our study combine with four patients in public database suggests an association between 21q21.1 microduplication of CXADR gene and patients with developmental delay. One patient with 21q22.13 microdeletion of DYRK1A shows association with microcephaly and scoliosis. Our findings helped pinpoint critical genes in the genotype-phenotype association with a high resolution of $0.1 \mathrm{Mb}$ and expanded the clinical features observed in patients with CNVs on the long arm of chromosome 21.

Keywords: Chromosome 21, Microarray, CNV, Genotype-phenotype association, CXADR, DYRK1A

\section{Background}

Down Syndrome (DS) is the most prevalent genetic disorder resulting in intellectual disability, which is usually caused by an extra copy of chromosome 21 . It is estimated that 1 in 700 newborn babies in United States are diagnosed with DS [1]. The phenotypes of DS frequently include congenital heart disease, intellectual disability, developmental abnormity and dysmorphic features [2].

\footnotetext{
* Correspondence: shibo-li@ouhsc.edu

Genetics Laboratory, University of Oklahoma Health Sciences Center, $1122 \mathrm{NE}$ 13th Street, Suite 1400, Oklahoma City, OK 73104, USA
}

Despite the fact that DS is mainly caused by trisomy 21 , the genotype-phenotype association of typical DS features is yet to be determined.

Down Syndrome Critical Region (DSCR) hypothesis failed to provide solid evidence on the proposed theory of minimum gene responsible for all major DS phenotypes caused by a gene dosage effect [3-6]. Meanwhile, under limited circumstances partial monosomy 21 and partial trisomy 21 have been found to provide better understanding on the genotype-phenotype association of chromosome 21 [7-10]. Phenotypes with partial

(C) The Author(s). 2018 Open Access This article is distributed under the terms of the Creative Commons Attribution 4.0 International License (http://creativecommons.org/licenses/by/4.0/), which permits unrestricted use, distribution, and 
duplication or deletion of chromosome 21q are found to be highly variable among patients For instance, a child with Intellectual disability and dysmorphologic features of DS but without congenital heart disease was found to have a 2.78-Mb duplication on chromosome 21q22.11 [11]. Partial deletion of 21q21.1 are found to be associated with intellectual disability while deletion of 21q22.11 are considered associated with neurobehavioral disorder [8]. Despite the efforts to link DS clinical features with genes and regions, the association map resolution is low and details still remain incomplete.

Instead of trying to find a DSCR, our study focused on finding specific genotype-phenotype associations by investigating rare patients which involved a partial CNV on chromosome 21. Advancements in technology in comparative genomic hybridization $(\mathrm{CGH})$ microarray enable laboratory to identify copy number variations (CNVs) on chromosome 21 as small as $10 \mathrm{k}$ base pairs. From 2008 to 2018, 2768 samples were collected at the Genetics Laboratory at University of Oklahoma Health Sciences Center (OUHSC). During this period, we identified six patients with partial duplication and seven patients with partial deletion of chromosome 21. Among 13 patients with CNVs, two patients are related while others are independent. In this study, we report the molecular and clinical relationship of chromosomal imbalance on chromosome 21 and compare our results with current public data and literature to provide new way to naming patient with certain phenotypes.

\section{Methods}

\section{Patients}

The study was approved by the Institutional Review Board (IRB) of the University of Oklahoma. IRB number was 5938 and the reference number was 670,840 . Retrospectively, 2768 pediatric patients sample were collected from 2008 to 2018 at the Genetics Laboratory at OUHSC. In-house software was developed to extract CNVs based on the following criteria:

1. CNVs only on chromosome 21, exclude whole chromosome 21 duplication/deletion and concurrent CNVs on other chromosomes.

2. CNV length larger than $100 \mathrm{~kb}$.

3. CNV mean $\log 2$ ratio absolute value larger than 0.3.

4. CNV not overlap with common CNVs and segmental duplication regions.

After filtration, CNVs were manually curated to eliminate false positive cases based on background signal noise. A total of 13 samples were identified, six samples displayed partial duplication and seven samples showed partial deletion. The clinical information of the patients is summarized in Table 1.

\section{CGH microarray}

Fresh blood samples were collected for this study and genomic DNA was extracted from peripheral white blood cells according to our standard operating using Nucleic Acid Isolation System (QuickGene-610 L, FUJIFILM Corporation, Tokyo, Japan). Patient D1's CGH microarray was performed on a $385-\mathrm{K}$ oligonucleotide chip and all other samples were performed on a CGH $720 \mathrm{~K}$ Whole-Genome Tiling v3.0 array (Roche NimbleGen, Inc., Madison, WI) according to the manufacturer's protocol with minor modifications. As an internal hybridization control for each experiment, an opposite sex DNA came from normal population individuals pooled use as reference DNA (Promega Corporation, Madison, WI). Both the patients' DNA and reference DNA were labeled with either Cyanine $3(\mathrm{Cy}-3)$ or Cyanine $5(\mathrm{Cy}-5)$ by random priming (Trilink Biotechnologies, San Diego, CA) and then hybridized to the chip via incubation in the MAUI hybridization system (Biomicro Systems, Inc., Salt Lake City, UT). After $18 \mathrm{~h}$ of hybridization at $42{ }^{\circ} \mathrm{C}$, slides were washed and scanned using an MS200 (Roche NimbleGen, Inc.). NimbleScan version 2.4 and the SignalMap version 1.9 were applied for data analysis (NimbleGen System Inc., Madison, WI). CGH microarray results were analyzed referring to University of California Santa Cruz (UCSC) Genome Browser (GRCh37/hg19) (http://genome.ucsc. edu/cgi-bin/hgGateway). Frequently affected regions that were recently identified as copy number polymorphisms were excluded from data analysis according to the Chromosome Number Variation (CNV) database in our lab and genomic variants in human genome (Build 37). Variants of interest were compared to disease-causing genes in DECIPHER v8.7 (Database of Chromosomal Imbalance and Phenotype in Humans using Ensembl Resources) (decipher.sanger.ac.uk/index), DGV (Database of Genomic Variants) (dgv.tcag.ca/dgv/app/home), ClinVar (www.ncbi.nlm.nih.gov/clinvar) and OMIM (www.omim.org). The patient's clinical phenotype and variants of interest were compared with available information from published reports.

\section{Results \\ Duplications}

Six patients (S1, S2, S3, S4, S5 and S6) were identified with duplication on chromosome 21. The size of chromosome 21 duplications ranged from $0.1 \mathrm{Mb}$ to 1.2 Mb (Table 1, Fig. 1, and Additional file 1: Figure S1). Among the duplications, one $\mathrm{CNV}$ at $21 \mathrm{q} 21.1$ was maternally inherited by patient S3 from patient S4 and presented in another unrelated patient (S1) that includes the CXADR gene (Figs. 1 and 2). These three patients share the phenotype of developmental delay while patient S3 also demonstrated pulmonary stenosis and 
Table 1 Molecular profile of patients

\begin{tabular}{|c|c|c|c|c|c|c|}
\hline Patient \# & Sex & Age at study & Chr21 location (hg19) & Gain/Loss & Size of CNVs (Mb) & Clinical features \\
\hline DECIPHER280573 & $\mathrm{F}$ & $14 y$ & $18,582,895-18,983,265$ & Gain & 0.4 & $\begin{array}{l}\text { DD, Intrauterine growth retardation, } \\
\text { microcephaly, alopecia }\end{array}$ \\
\hline S4 & $\mathrm{F}$ & 32 y & $18,776,205-19,072,251$ & Gain & 0.3 & DD, Mother of S3 \\
\hline S1 & M & $2 y$ & $18,781,100-18,885,813$ & Gain & 0.1 & $\begin{array}{l}\text { DD, cleft palate, microcephaly, failure } \\
\text { to thrive }\end{array}$ \\
\hline S3 & $\mathrm{F}$ & $7 y$ & $18,781,100-19,071,857$ & Gain & 0.3 & $\begin{array}{l}\text { DD, pulmonary stenosis, autism, } \\
\text { mild dysmorphic, daughter of S4 }\end{array}$ \\
\hline DECIPHER273421 & M & $4 y$ & $18,791,730-19,136,039$ & Gain & 0.3 & Intellectual disability \\
\hline DECIPHER301183 & $\mathrm{F}$ & $2 y$ & $18,819,200-19,036,035$ & Gain & 0.2 & $\begin{array}{l}\mathrm{DD} \text {, microcephaly, seizures, hearing } \\
\text { and visual abnormality }\end{array}$ \\
\hline DECIPHER257242 & $\mathrm{F}$ & $7 y$ & $18,888,629-18,983,265$ & Gain & 0.1 & $\begin{array}{l}\text { DD, Intrauterine growth retardation, } \\
\text { intellectual disability }\end{array}$ \\
\hline D6 & $\mathrm{F}$ & $2 y$ & $21,427,690-24,133,154$ & Loss & 2.7 & DD \\
\hline D4 & $\mathrm{F}$ & 33 y & $22,271,313-23,399,894$ & Loss & 1.1 & Mother with Intrauterine fetal demise \\
\hline D5 & $\mathrm{F}$ & $4 y$ & $23,793,678-23,948,945$ & Loss & 0.1 & DD, epilepsia partialis continua \\
\hline D3 & M & $2 \mathrm{~m}$ & $23,840,342-23,941,319$ & Loss & 0.1 & Congenital coronary anomaly \\
\hline D7 & M & $6 y$ & $24,289,038-24,396,084$ & Loss & 0.1 & Seizures \\
\hline S2 & M & $3 y$ & $28,212,197-29,423,946$ & Gain & 1.2 & $\begin{array}{l}\text { Preauricular skin tag, eye pterygium, } \\
\text { speech delay }\end{array}$ \\
\hline D2 & $\mathrm{F}$ & $1 y$ & $31,005,158-31,236,003$ & Loss & 0.2 & Facial dysmorphic features \\
\hline S6 & $\mathrm{F}$ & $9 d$ & $35,902,679-36,149,583$ & Gain & 0.2 & Diaphragmatic hernia \\
\hline S5 & M & $4 y$ & $37,474,069-37,611,689$ & Gain & 0.1 & Pain insensitivity and minor dysmorphisms \\
\hline D1 & M & $10 y$ & $37,540,692-39,328,135$ & Loss & 1.7 & $\begin{array}{l}\text { Microcephaly, levocurvature of } \\
\text { thoracolumbar spine }\end{array}$ \\
\hline Yamamoto, 2011 & F & $13 y$ & $38,528,931-39,009,341$ & Loss & 0.4 & DD, seizures, mild brain atrophy \\
\hline Courcet, 2012 & $\mathrm{~F}$ & $4 y$ & $38,722,631-38,791,771$ & Loss & 0.1 & Microcephaly, DD, ataxic gait, seizures \\
\hline DECIPHER258106 & $\mathrm{F}$ & N/A & $38,865,151-38,885,792$ & Loss & 0.1 & $\begin{array}{l}\text { Microcephaly, scoliosis, deeply set eye, } \\
\text { Intrauterine growth retardation, short nose, } \\
\text { sparse scalp hair, Hypoglycemia, DD, seizures }\end{array}$ \\
\hline Van Bon, 2011 & F & $>20 y$ & $38,874,630-38,927,130$ & Loss & 0.1 & $\begin{array}{l}\text { Microcephaly, DD, mild brain atrophy, } \\
\text { anxious and autistic behaviour }\end{array}$ \\
\hline
\end{tabular}

Note: $F$ female, $M$ male, $y$ year, $m$ month, $d$ day, $D D$ developmental delay

autism. A 1.2-Mb duplication at $21 \mathrm{q} 21.3$ presented in patient S2 with preauricular skin tag, eye pterygium and speech delay (Fig. 2). Two genes, ADAMTS1 and ADAMTS5, have been identified on this CNV. Diaphragmatic hernia presented in patient $\mathrm{S} 6$ with a $0.2-\mathrm{Mb}$ duplication at 21q22.12 which includes the RCAN1 and CLIC6 genes (Fig. 2). Also with duplication at 21q22.12, another patient (S5) showed pain insensitivity along with minor dysmorphism. Two protein-coding genes, CBR3 and DOPEY2, are located in this duplication region (Fig. 2).

\section{Deletions}

Seven patients (D1, D2, D3, D4, D5, D6 and D7) were identified with deletion on chromosome 21 ranged from $0.1 \mathrm{Mb}$ to $2.7 \mathrm{Mb}$.Five patients (D3, D4, D5, D6 and D7) with various sizes of deletion at 21q21.1-q21.2 presented clinical features which included developmental delay, intrauterine fetal demise, epilepsia partialis continua, congenital coronary anomaly and seizures (Table 1, Figs. 1 and 2 and Additional file 1: Figure S1). The NCAM2 gene is located in this 21q21.1-q21.2 deletion region (Figs. 1 and 2). Patient D2 had a phenotype of facial dysmorphic features and a $0.2-\mathrm{Mb}$ deletion on 21q21.3 that includes the GRIK1 gene (Figs. 1 and 2). Patient D1 presented with a deletion of $1.7 \mathrm{Mb}$ at 21q22.12-q22.13 that includes four OMIM genes: CLDN14, HLCS, DYRKIA and KCNJ6 (Figs. 1 and 2). The phenotype associated with this patient was microcephaly and levocurvature of the thoracolumbar spine.

\section{Discussion}

Microduplication 21q21.1

The microduplication on 21q21.1 was found in three patients S1, S3 and S4. This CNV was inherited from S4 to S3. Published reports of this CNV are rare but four patients (DECIPHER 257242, 301,183, 273,421 and 


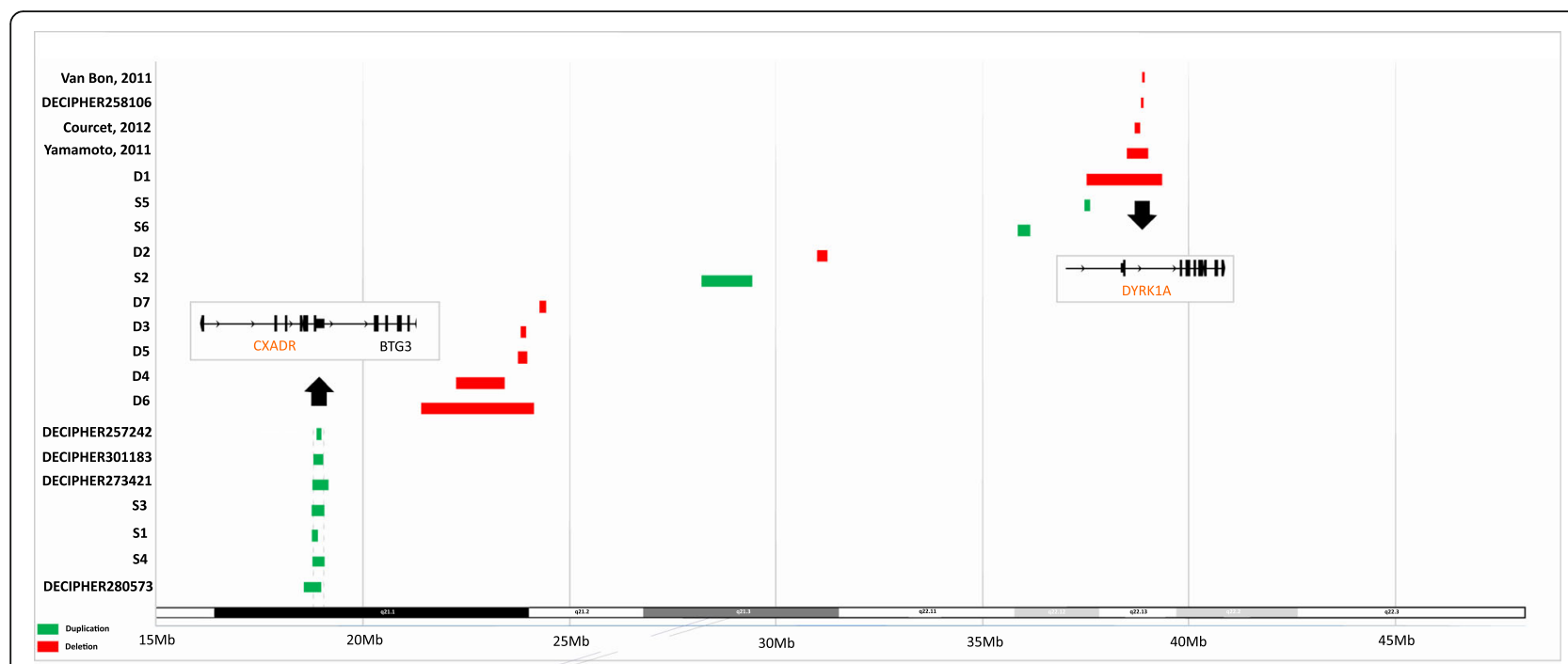

Fig. 1 CNVs identified in this study and previous reported patients along chromosome 21. Note: Red color indicate copy number loss, green color indicate copy number gain. The order of the case follows Table 1

280,573) were found to have similar duplication segments and shared phenotypes such as developmental delay and intellectual disability [12]. There are two protein-coding genes, CXADR and BTG3, in this region. The CNV identified with patient $\mathrm{S} 1$ is within the $0.3-\mathrm{Mb}$ region but is smaller and only includes the CXADR gene. Patient S1 also displayed the same developmental delay features that patients S3 and S4 possessed.

The CXADR and BTG3 genes were found to be expressed during early brain development and a balanced expression of BTG3 is critical for neuron differentiation in the forebrain [13, 14]. BTG3 is upregulated in trisomic fibroblasts compared to a control indicating a gene dosage effect on heart tissues [15]. Considering patient S3 displayed pulmonary stenosis while patient S1 did not, and the extra duplicated region of S3 includes BTG3, this gene could potentially contribute to this clinical distinction. BTG3 has also been linked with autism because of its role in cellular apoptosis and responses to redox changes $[16,17]$. The protein product of BTG3 has also been found to have a critical impact on cell growth and differentiation of

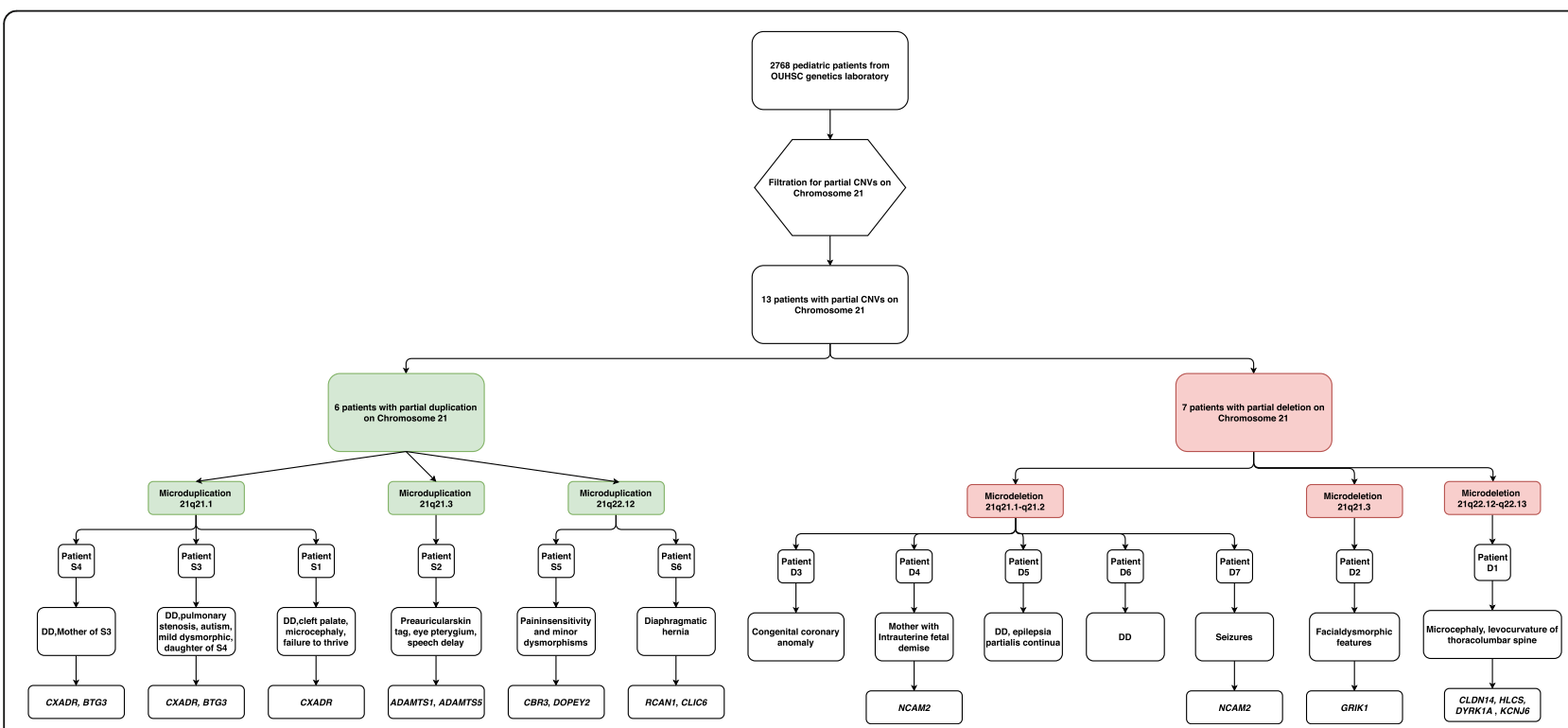

Fig. 2 Flow chart of CNVs analysis and corresponding phenotype with OMIM genes. Note: Pink color indicate copy number loss, light green color indicate copy number gain. $F=$ female, $M=$ male, $y=$ year, $m=$ month, $d=$ day, $D D=$ developmental delay 
other cells like $\mathrm{T}$ lymphocytes, fibroblasts and epithelial cells [18].

CXADR has been associated with developmental delay in two patients with larger $\mathrm{CNV}$ deletions of $7.9 \mathrm{Mb}$ and $8.5 \mathrm{Mb}[19,20]$. Combined with our three cases and the four DECIPHER patients mentioned above, it shows a strong connection between the irregular expression levels of CXADR and developmental disorders [19]. Coxsackievirus and adenovirus receptor (CAR) is a protein encoded by the CXADR gene. CAR has dual function as a receptor in the immune response against virus and a signal transduction molecule during neurological system development [21]. CAR is highly expressed in tissues like brain and heart in the early development; it is mainly expressed in endothelial cells and cardiac cells postnatally [22, 23]. Excessive expression of CAR has been link to activation of mitogen-activated protein kinase (MAPK) pathway in heart which might contribute to the hyper M1 inflammatory response in DS [24]. Additional follow up with Cardiologist might provide better understanding on the clinical significance of CXADR gene for these three patients. Our study narrowed down the critical region of patients with microduplication 21q21.1 features from $0.4 \mathrm{Mb}$ to $0.1 \mathrm{Mb}$ and highlighted the clinical relevance of CXADR gene as a potential cause for developmental delay, abnormal development of cardio myocytes and intellectual disability $[25,26]$.

\section{Microduplication 21q21.3}

One patient S2 was found to have a 1.2-Mb microduplication at $21 \mathrm{q} 21.3$ with a preauricular skin tag, eye pterygium and speech delay. Our patient's CNV is the first ever reported on this region which includes ADAMTS1 and ADAMTS5. The functions of these genes are not well understood but ADAMTS1 was found to be associated with various inflammatory processes and cachexia and ADAMTS5 may involve destruction of the aggrecan, a cartilage proteoglycan [20]. One case of an $8.8-\mathrm{Mb}$ deletion which encompasses both ADAMTS1 and ADAMTS5 was reported before with a similar speech delay phenotype as patient S2 but without other clinical features [20]. Further study is needed to better understand the clinical significance of this CNV.

\section{Microduplication 21q22.12}

One patient S6, a 9-day-old female with a diaphragmatic hernia, was found to have a $0.2-\mathrm{Mb}$ microduplication at 21q22.12. There are two genes in this region, RCAN1 and CLIC6. Among them, RCAN1 has been linked to contribute to the intellectual disability and neuronal degeneration in Alzheimer's disease [27]. Multiple studies using animal models and transcriptome analysis demonstrated the important function by RCAN1 in regulation of the anxiogenic response and oxidative stress-induced apoptosis [28-30]. Unfortunately, we were limited by the age of our patient (S6) so no other information is available other than the presence of the diaphragmatic hernia, which has not been found to be associated with either RCAN1 or CLIC6 before. The function of CLIC6 is not exactly clear.

Another patient S5 was found to have a $0.1-\mathrm{Mb}$ microduplication about 1.3 $\mathrm{Mb}$ downstream of S6's CNV. Literature research found several patients had this CNV and it mostly resulted in nervous system disorders or developmental delay (DECIPHER 276835,287,879, 317,546 etc.) [12]. Interestingly, one case reported a $6.5-\mathrm{Mb}$ deletion on $21 \mathrm{q} 22.12$ and the patient also showed signs of pain insensitivity, however the genotype is deletion instead of duplication, the overlap region coordinate is chr21: 37,474,069-37,554,434 (hg19) and CBR3 gene is in this region [31]. Two genes, CBR3 and DOPEY2, are found in the duplicated region of patient S5. These genes were both found to be closely related with DS phenotypes and be subject to the gene dosage effect causing intellectual disability and early onset of Alzheimer's Disease [32-34]. However, no other pain insensitivity information was found to be associated with these genes.

\section{Microdeletion 21q21.1-q21.2}

Five patients (D3, D4, D5, D6 and D7) were found with various sizes of deletion at 21q21.1-q21.2. Patient D6 had a 2.7-Mb microdeletion on 21q21.1-q21.2. Three patients (D3, D4 and D5) also had microdeletions of $0.1 \mathrm{Mb}$, $1.1 \mathrm{Mb}$ and $0.1 \mathrm{Mb}$, respectively, within the $2.7-\mathrm{Mb}$ microdeletion region of patient D6. Patient D7 had a $0.1-\mathrm{Mb}$ microdeletion on 21q21.2 with a clinical feature of seizures. A previous study showed one patient (DECIPHER 319386) had a similar, but slightly smaller, microdeletion compared to patient D6. DECIPHER 319386 had macrocephaly, autistic behavior and delayed speech and language development but no common phenotypic features were found between patient D6 and DECIPHER 319386. A common feature found in patients D5 and D6 was developmental delay. Patient D4 was a mother who experienced an intrauterine fetal demise. A congenital coronary anomaly was reported in D3.

On the molecular level, NCAM2 overlaps with the microdeletion on patients D4 and D6. NCAM2 is believed to be associated with certain DS phenotypes because, as the expression levels change, multiple folds related to the homotypic adhesion properties of cells will be altered [35]. NCAM2 also has been suggested as a candidate gene for autism because it is highly expressed in the brain and nervous systems [20,36-38]. There are no known protein-coding genes in the microdeletion region of patients D3, D5 and D7 which suggests an alternative explanation other than CNVs is responsible for their phenotype. 


\section{Microdeletion 21q21.3}

One patient D2 had a microdeletion on 21q21.3 the size of $0.2 \mathrm{Mb}$ and was found to be within the $0.4-\mathrm{Mb}$ microdeletion region of DECIPHER 257308. Limited by the young age of patient D2 (one-year-old), only facial dysmorphic features were observed while DECIPHER 257308 displayed aggressive behavior, generalized tonic-clonic seizures and neurological speech impairment. GRIK1, a gene that encodes for a glutamatergic receptor subunit, is found in this microdeletion region. Glutamate is the most widely distributed excitatory neurotransmitter in the central nervous system acting on ionotropic and metabotropic receptors. Expression of GRIK1 was found be to significantly lower in the hippocampus of DS patients and receptors were overexpressed in various areas of the brain $[39,40]$. Also, trisomic animals were found to respond to glutamatergic stimuli differed from normal animals as well [41]. Based on the potential gene-dosage effect of GRIK1 and the phenotypes displayed by DECIPHER 257308 which involved excitability, the GRIK1 gene should be considered to be a strong candidate gene responsible for DS phenotypes.

\section{Microdeletion 21q22.12-q22.13}

One patient $\mathrm{D} 1$ had a $1.7-\mathrm{Mb}$ deletion on 21q22.12-q22.13, which includes four OMIM genes: CLDN14, HLCS, DYRK1A and KCNJ6. Yamamoto et al. (2011) reported two cases with mosaic deletions on 21q22qter and one case with a 0.4-Mb deletion within the 21q22.12-q22.13 microdeletion region. One of the mosaic deletion cases displayed an identical phenotype to patient D1 which included microcephaly and scoliosis [42]. In addition, a DECIPHER case (258106) that had a $0.2-\mathrm{Mb}$ microdeletion within the same region also had microcephaly and scoliosis. DYRK1A is the only gene affected in all three cases and is reported to play a role in neurogenesis and neural differentiation [43]. Previous studies showed an association between DYRK1A and microcephaly had been well established and around half of the patients also displayed scoliosis [44, 45]. Single Nucleotide Variances and small INDELs on this genes also demonstrate similar phenotype of microdeletion on $21 \mathrm{q} 22.13$ that reaffirms this strong association between DYRK1A gene and syndrome with microcephaly and scoliosis $[44,45]$.

\section{Conclusions}

In conclusion, our study expands the knowledge of the phenotypic consequences of CNVs on the long arm of chromosome 21. While the microduplications are associated with developmental delay, microcephaly, facial dysmorphic features, pulmonary stenosis, autism, preauricular skin tag, eye pterygium, speech delay and pain insensitivity, microdeletions are associated with developmental delay, microcephaly, intrauterine fetal demise, epilepsia partialis continua, congenital coronary anomaly and seizures. We suggest the CXADR gene is involved with developmental delay in patients with 21q21.1 microduplication and we provide additional evidence that DYRK1A is associated with microcephaly and scoliosis in patients with a $21 \mathrm{q} 22$ microdeletion. Both CXADR and DYRK1A are ranked high in the haploinsufficiency index of chromosome 21 gene list that indicates one allele with loss of function variant will result in a recognizable phenotype [46]. It also been found that haploinsufficient genes are more sensitive to dosage effect that might contribute to some of the DS phenotypes [47]. Our study demonstrates the clinical relevance of small CNVs as low as $0.1 \mathrm{Mb}$ during CGH Microarray diagnostic testing and underlines the importance of prudent clinical interpretation of these CNVs. With the Next-generation sequencing (NGS) technology ability to detecting both single nucleotide variants and copy number variation in one test, Whole Genome Sequencing (WGS) could one day serve a more importance role in further establish the genotype-phenotype association. Large cohort studies with specific phenotypes subgroups will also be helpful to further our understanding of the genotype-phenotype association on chromosome 21.

\section{Additional file}

Additional file 1: Figure S1. CGH microarray results of patients. Each sub figure shows log2 ratio along affected chromosome 21, y axis shows $\log 2$ ratio and $x$ axis physical location. (TIF $6186 \mathrm{~kb}$ )

\section{Acknowledgements}

The authors would like to thank the patients participating in this study and the technologists, including Hui Pang of OUHSC Genetics Laboratory, for their technical support.

\section{Availability of data and materials}

All data generated or analysed during this study are included in this published article and its supplementary information files.

\section{Authors' contributions}

WL gained the IRB approval, gathered clinical information, interpreted the array $\mathrm{CGH}$ data, and drafted the manuscript. XW performed the array $\mathrm{CGH}$ analysis and participated array CGH data interpretation. SL conceived this study and helped draft the manuscript. All authors read and approved the final manuscript.

Ethics approval and consent to participate

This study (\#5938) was approved by University of Oklahoma Institutional Review Board for the Protection of Human Subjects.

Consent for publication

Not applicable.

Competing interests

The authors declare that they have no competing interests.

\section{Publisher's Note}

Springer Nature remains neutral with regard to jurisdictional claims in published maps and institutional affiliations. 
Received: 6 March 2018 Accepted: 19 July 2018 Published online: 10 August 2018

\section{References}

1. Parker SE, Mai CT, Canfield MA, Rickard R, Wang Y, Meyer RE, Anderson P, Mason CA, Collins JS, Kirby RS, et al. Updated National Birth Prevalence estimates for selected birth defects in the United States, 2004-2006. Birth Defects Res A Clin Mol Teratol. 2010;88(12):1008-16.

2. Scriver CR. The metabolic and molecular bases of inherited disease. 7th ed. New York: McGraw-Hill, Health Professions Division; 1995.

3. Delabar JM, Theophile D, Rahmani Z, Chettouh Z, Blouin JL, Prieur M, Noel $B$, Sinet PM. Molecular mapping of twenty-four features of Down syndrome on chromosome 21. Eur J Hum Genet. 1993;1(2):114-24.

4. Kahlem P, Sultan M, Herwig R, Steinfath M, Balzereit D, Eppens B, Saran NG, Pletcher MT, South ST, Stetten G, et al. Transcript level alterations reflect gene dosage effects across multiple tissues in a mouse model of Down syndrome. Genome Res. 2004;14(7):1258-67.

5. Amano K, Sago H, Uchikawa C, Suzuki T, Kotliarova SE, Nukina N, Epstein CJ, Yamakawa K. Dosage-dependent over-expression of genes in the trisomic region of Ts1Cje mouse model for Down syndrome. Hum Mol Genet. 2004; 13(13):1333-40.

6. Crombez EA, Dipple KM, Schimmenti LA, Rao N. Duplication of the Down syndrome critical region does not predict facial phenotype in a baby with a ring chromosome 21. Clin Dysmorphol. 2005;14(4):183-7.

7. Doran E, Keator D, Head E, Phelan MJ, Kim R, Totoiu M, Barrio JR, Small GW, Potkin SG, Lott IT. Down syndrome, partial trisomy 21, and absence of Alzheimer's disease: the role of APP. J Alzheimers Dis. 2017;56(2):459-70.

8. Errichiello E, Novara F, Cremante A, Verri A, Galli J, Fazzi E, Bellotti D, Losa L, Cisternino M, Zuffardi O. Dissection of partial 21q monosomy in different phenotypes: clinical and molecular characterization of five cases and review of the literature. Mol Cytogenet. 2016;9(1):21.

9. Pelleri MC, Cicchini E, Locatelli C, Vitale L, Caracausi M, Piovesan A, Rocca A, Poletti G, Seri M, Strippoli P, et al. Systematic reanalysis of partial trisomy 21 cases with or without Down syndrome suggests a small region on $21 \mathrm{q} 22.13$ as critical to the phenotype. Hum Mol Genet. 2016;25(12):2525-38.

10. Simioni M, Steiner CE, Gil-da-Silva-Lopes VL. De novo double reciprocal translocations in addition to partial monosomy at another chromosome: a very rare case. Gene. 2015;573(1):166-70.

11. Weisfeld-Adams JD, Tkachuk AK, Maclean KN, Meeks NL, Scott SA. A de novo 2.78-Mb duplication on chromosome 21q22.11 implicates candidate genes in the partial trisomy 21 phenotype. NPJ Genom Med. 2016;1

12. Firth HV, Richards SM, Bevan AP, Clayton S, Corpas M, Rajan D, Van Vooren S, Moreau Y, Pettett RM, Carter NP. DECIPHER: database of chromosomal imbalance and phenotype in humans using Ensembl resources. Am J Hum Genet. 2009;84(4):524-33.

13. Efron D. Autism: current theories and evidence (hbk). J Paediatr Child Health. 2010;46(1-2):70.

14. Rost I, Fiegler H, Fauth C, Carr P, Bettecken T, Kraus J, Meyer C, Enders A Wirtz A, Meitinger T, et al. Tetrasomy 21 pter-->q21.2 in a male infant without typical Down's syndrome dysmorphic features but moderate mental retardation. J Med Genet. 2004;41(3):e26.

15. Piccoli C, Izzo A, Scrima R, Bonfiglio F, Manco R, Negri R, Quarato G, Cela O, Ripoli M, Prisco M, et al. Chronic pro-oxidative state and mitochondrial dysfunctions are more pronounced in fibroblasts from Down syndrome foeti with congenital heart defects. Hum Mol Genet. 2013;22(6):1218-32.

16. Molloy CA, Keddache M, Martin LJ. Evidence for linkage on 21q and 7q in a subset of autism characterized by developmental regression. Mol Psychiatry. 2005;10(8):741-6.

17. Chauhan A, Chauhan V. Oxidative stress in autism. Pathophysiology. 2006; 13(3):171-81.

18. Matsuda S, Rouault J, Magaud J, Berthet C. In search of a function for the TIS21/PC3/BTG1/TOB family. FEBS Lett. 2001;497(2-3):67-72

19. Petit F, Plessis G, Decamp M, Cuisset JM, Blyth M, Pendlebury M, Andrieux J. 21q21 deletion involving NCAM2: report of 3 cases with neurodevelopmental disorders. Eur J Med Genet. 2015;58(1):44-6.

20. Haldeman-Englert CR, Chapman KA, Kruger H, Geiger EA, McDonald-McGinn DM, Rappaport E, Zackai EH, Spinner NB, Shaikh TH. A de novo 8.8-Mb deletion of 21q21.1-q21.3 in an autistic male with a complex rearrangement involving chromosomes 6, 10, and 21. Am J Med Genet A. 2010;152A(1): 196-202.
21. Wilcock DM. Neuroinflammation in the aging Down syndrome brain; lessons from Alzheimer's disease. Curr Gerontol Geriatr Res. 2012;2012:170276.

22. Kashimura T, Kodama M, Hotta Y, Hosoya J, Yoshida K, Ozawa T, Watanabe R, Okura Y, Kato K, Hanawa H, et al. Spatiotemporal changes of coxsackievirus and adenovirus receptor in rat hearts during postnatal development and in cultured cardiomyocytes of neonatal rat. Virchows Arch. 2004;444(3):283-92

23. Chen JW, Zhou B, Yu QC, Shin SJ, Jiao K, Schneider MD, Baldwin HS, Bergelson JM. Cardiomyocyte-specific deletion of the coxsackievirus and adenovirus receptor results in hyperplasia of the embryonic left ventricle and abnormalities of sinuatrial valves. Circ Res. 2006;98(7):923-30.

24. Yuen S, Smith J, Caruso L, Balan M, Opavsky MA. The coxsackie-adenovirus receptor induces an inflammatory cardiomyopathy independent of viral infection. J Mol Cell Cardiol. 2011;50(5):826-40.

25. Caceres M, Lachuer J, Zapala MA, Redmond JC, Kudo L, Geschwind DH, Lockhart DJ, Preuss TM, Barlow C. Elevated gene expression levels distinguish human from non-human primate brains. Proc Natl Acad Sci U S A. 2003;100(22):13030-5.

26. Iurov I, Vorsanova SG, Saprina EA, lurov lu B. Identification of candidate genes of autism on the basis of molecular cytogenetic and in silico studies of the genome organization of chromosomal regions involved in unbalanced rearrangements. Genetika. 2010;46(10):1348-51.

27. Hoeffer CA, Dey A, Sachan N, Wong H, Patterson RJ, Shelton JM, Richardson JA, Klann E, Rothermel BA. The Down syndrome critical region protein RCAN1 regulates long-term potentiation and memory via inhibition of phosphatase signaling. J Neurosci. 2007;27(48):13161-72

28. Wong H, Levenga J, Cain P, Rothermel B, Klann E, Hoeffer C. RCAN1 overexpression promotes age-dependent mitochondrial dysregulation related to neurodegeneration in Alzheimer's disease. Acta Neuropathol. 2015;130(6):829-43.

29. Patel A, Yamashita N, Ascano M, Bodmer D, Boehm E, Bodkin-Clarke C, Ryu YK, Kuruvilla R. RCAN1 links impaired neurotrophin trafficking to aberrant development of the sympathetic nervous system in Down syndrome. Nat Commun. 2015;6:10119.

30. Wu Y, Song W. Regulation of RCAN1 translation and its role in oxidative stress-induced apoptosis. FASEB J. 2013;27(1):208-21.

31. Shirley MD, Frelin L, Lopez JS, Jedlicka A, Dziedzic A, Frank-Crawford MA, Silverman W, Hagopian L, Pevsner J. Copy number variants associated with 14 cases of self-injurious behavior. PLoS One. 2016;11(3):e0149646.

32. Fujita H, Torii C, Kosaki R, Yamaguchi S, Kudoh J, Hayashi K, Takahashi T, Kosaki K. Microdeletion of the Down syndrome critical region at 21q22. Am J Med Genet A. 2010;152A(4):950-3.

33. Cho CK, Drabovich AP, Karagiannis GS, Martinez-Morillo E, Dason S, Dimitromanolakis A, Diamandis EP. Quantitative proteomic analysis of amniocytes reveals potentially dysregulated molecular networks in Down syndrome. Clin Proteomics. 2013;10(1):2.

34. Swaminathan S, Huentelman MJ, Corneveaux JJ, Myers AJ, Faber KM, Foroud T, Mayeux R, Shen L, Kim S, Turk M, et al. Analysis of copy number variation in Alzheimer's disease in a cohort of clinically characterized and neuropathologically verified individuals. PLoS One. 2012;7(12):e50640.

35. Paoloni-Giacobino A, Chen $\mathrm{H}$, Antonarakis SE. Cloning of a novel human neural cell adhesion molecule gene (NCAM2) that maps to chromosome region 21 q21 and is potentially involved in Down syndrome. Genomics. 1997;43(1):43-51.

36. Nielsen J, Gotfryd K, Li S, Kulahin N, Soroka V, Rasmussen KK, Bock E, Berezin $\checkmark$. Role of glial cell line-derived neurotrophic factor (GDNF)-neural cell adhesion molecule (NCAM) interactions in induction of neurite outgrowth and identification of a binding site for NCAM in the heel region of GDNF. J Neurosci. 2009;29(36):11360-76.

37. Kulahin N, Walmod PS. The neural cell adhesion molecule NCAM2/OCAM/ RNCAM, a close relative to NCAM. Adv Exp Med Biol. 2010;663:403-20.

38. Chen CP, Lin YH, Chou SY, Su YN, Chern SR, Chen YT, Town DD, Chen WL, Wang W. Mosaic ring chromosome 21, monosomy 21, and isodicentric ring chromosome 21: prenatal diagnosis, molecular cytogenetic characterization, and association with 2-Mb deletion of 21q21.1-q21.2 and 5-Mb deletion of 21q22.3. Taiwan J Obstet Gynecol. 2012;51(1):71-6.

39. Reynolds GP, Warner CE. Amino acid neurotransmitter deficits in adult Down's syndrome brain tissue. Neurosci Lett. 1988;94(1-2):224-7.

40. Arai Y, Mizuguchi M, Takashima S. Excessive glutamate receptor 1 immunoreactivity in adult Down syndrome brains. Pediatr Neurol. 1996; 15(3):203-6. 
41. Saud K, Arriagada C, Cardenas AM, Shimahara T, Allen DD, Caviedes R, Caviedes P. Neuronal dysfunction in Down syndrome: contribution of neuronal models in cell culture. J Physiol Paris. 2006;99(2-3):201-10.

42. Yamamoto T, Shimojima K, Nishizawa T, Matsuo M, Ito M, Imai K. Clinical manifestations of the deletion of Down syndrome critical region including DYRK1A and KCNJ6. Am J Med Genet A. 2011;155A(1):113-9.

43. Dowjat WK, Adayev T, Kuchna I, Nowicki K, Palminiello S, Hwang YW, Wegiel J. Trisomy-driven overexpression of DYRK1A kinase in the brain of subjects with Down syndrome. Neurosci Lett. 2007:413(1):77-81.

44. Courcet J-B, Faivre L, Malzac P, Masurel-Paulet A, Lopez E, Callier P, Lambert $\mathrm{L}$, Lemesle M, Thevenon J, Gigot N, et al. The DYRK1A gene is a cause of syndromic intellectual disability with severe microcephaly and epilepsy. J Med Genet. 2012;49(12):731-6.

45. Ji J, Lee H, Argiropoulos B, Dorrani N, Mann J, Martinez-Agosto JA, GomezOspina N, Gallant N, Bernstein JA, Hudgins L, et al. DYRK1A

haploinsufficiency causes a new recognizable syndrome with microcephaly, intellectual disability, speech impairment, and distinct facies. Eur J Hum Genet. 2015;23(11):1473-81.

46. Antonarakis SE. Down syndrome and the complexity of genome dosage imbalance. Nat Rev Genet. 2017;18(3):147-63.

47. Conrad B, Antonarakis SE. Gene duplication: a drive for phenotypic diversity and cause of human disease. Annu Rev Genomics Hum Genet. 2007:8:17-35.

Ready to submit your research? Choose BMC and benefit from:

- fast, convenient online submission

- thorough peer review by experienced researchers in your field

- rapid publication on acceptance

- support for research data, including large and complex data types

- gold Open Access which fosters wider collaboration and increased citations

- maximum visibility for your research: over $100 \mathrm{M}$ website views per year

At $\mathrm{BMC}$, research is always in progress.

Learn more biomedcentral.com/submissions 